\title{
Circulating soluble immune complexes containing pseudomonas antigens in cystic fibrosis
}

\author{
R W PITCHER-WILMOTT, R J LEVINSKY, AND D J MATTHEW \\ Department of Immunology, Institute of Child Health, and the Respiratory Unit, The Hospital for Sick \\ Children, London
}

SUMMARY In order to investigate whether circulating immune complexes containing Pseudomonas aeruginosa antigens mediate pulmonary damage in cystic fibrosis, we studied lung function, serum immune complex levels, and immunoglobulin concentrations in relationship to chronic pseudomonas colonisation in 69 affected children. Sixteen of the children with cystic fibrosis had increased levels of immune complexes which contained pseudomonas antigens. There was no significant relationship between lung function corrected for the effect of chronic pseudomonas colonisation and the presence of such complexes or increased levels of complexes detected by Clq binding or raised serum immunoglobulin concentrations. Our results suggest that these abnormalities in cystic fibrosis are secondary effects of chronic infection and they do not provide evidence for immune complex mediated lung damage in this disease.

Recurrent pulmonary infections account for most of the morbidity and mortality ${ }^{1}$ in cystic fibrosis (CF). Chronic colonisation with Pseudomonas aeruginosa (PA) is particularly likely to occur and is strongly associated with poor lung function. ${ }^{2}{ }^{3}$ High titres of precipitating antibodies to PA correlate with poor prognosis, ${ }^{24}$ and circulating immune complexes (IC) demonstrated by a variety of methods ${ }^{5-8}$ correlate both with PA infection ${ }^{7}$ and poor lung function. 910 Based on this evidence, it has been suggested that circulating IC may cause localised type III hypersensitivity reactions in the lungs and so produce secondary lung damage in CF. ${ }^{510}$

To investigate this hypothesis of lung damage mediated by circulating IC we have measured them in the sera of $69 \mathrm{CF}$ patients and analysed them for the presence of PA antigens using an immune complex splitting assay. We then studied the relationship between such complexes, lung function, and chronic PA colonisation by analysis of variance to examine whether the association of circulating IC with poor lung function is causative.

\section{Patients and methods}

Sixty-nine CF children who were bled for a previous study and who have been reported ${ }^{3}$ were studied. Their ages ranged from 2 to 15 (mean 9) years. Lung function data from that earlier study included forced expiratory flow at $25 \%$ vital capacity $\left(\mathrm{FEF}^{25}\right)$, measured from a maximal expiratory flow volume curve, and residual volume to total lung capacity ratio (RV/TLC), measured by whole body plethysmography. These were the most sensitive measures of airflow obstruction and hyperinflation in the earlier analyses. ${ }^{3}$

Cultures of sputum or cough swabs were obtained every 2 months from these patients and if three consecutive cultures during a period of at least 3 months were positive for PA, the patient was defined as having persistent colonisation with PA.

Blood samples from these patients were separated at room temperature within 2 hours of collection and the sera were stored in aliquots at $-70^{\circ} \mathrm{C}$.

Immunoglobulin concentrations. Serum concentrations of IgG, IgA, and IgM were measured by radial immunodiffusion $^{11}$ and results expressed as $\mathrm{IU} / \mathrm{ml}$.

Circulating immune complexes. Two methods were used-namely, a radiolabelled ${ }^{125} \mathrm{I}-\mathrm{Clq}$ binding assay (Clq BA) ${ }^{12}$ and polyethylene glycol (PEG) precipitation. ${ }^{13} \mathrm{Clq} \mathrm{BA}$ measures precipitation of ${ }^{125} \mathrm{I}$-Clq by IC in the presence of $3 \%$ polyethylene glycol and detects IgM IC and certain subclasses of IgG in IC. Results were expressed as a percentage of the radioactive counts precipitable by $10 \%$ trichloroacetic acid.

IgG and IgM IC were also measured independently in the PEG precipitation assay. ${ }^{13}$ Serum samples 577 
$(250 \mu \mathrm{l})$ were mixed with $50 \mu \mathrm{l} 12 \%$ PEG in EDTA buffer pH 7.4 and, after overnight incubation at $4{ }^{\circ} \mathrm{C}$, precipitated IC were assayed for immunoglobulin content in high sensitivity agar diffusion plates. ${ }^{11}$ Each result was expressed as a percentage of the immunoglobulin concentration in the original serum.

Immune complex dissociation assay. A modification of the complex splitting assay described by Paganelli et al. ${ }^{14}$ was used. The IgG fraction of a high titre rabbit antiserum to PA strains 'PAO' was prepared by absorption with sepharose-staphylococcal protein A (Sigma Chemical Co., St Louis, USA) and after one wash in Tris-HCl buffer (pH 7.6) the IgG was dissociated from the sepharose by $0.2 \mathrm{~mol} / \mathrm{l}$ glycine$\mathrm{HCl}$ buffer ( $\mathrm{pH} \mathrm{2.6)}$. The resulting preparation was neutralised with solid Tris and then tested by immunoelectrophoresis against PAO cell wall extract, Aspergillus fumigatus serodiagnostic antigen (Bencard Allergy Service, Brentford, Middlesex), and normal human serum. It reacted only with the PAO extract. Positive control PA antigen containing IC in 2- and 4-fold antigen excess were prepared after appropriate titration of the IgG preparation (1 to $10 \mu \mathrm{g} / \mathrm{ml}$ ) wtih PAO antigen $(163 \mathrm{mg} / \mathrm{ml})$ using ${ }^{125}$ I labelled PAO as a tracer. ${ }^{14}$

IC were obtained from test and control sera by precipitation in 2\% PEG (as before) and the IC from $100 \mu \mathrm{l}$ serum were resuspended in the same volume of $0.2 \mathrm{~mol} / 1$ glycine- $\mathrm{HCl}$ buffer (pH 2.6). This solution $(50 \mu \mathrm{l})$ was incubated in each of two polystyrene autoanalyser cups for 18 hours at $22^{\circ} \mathrm{C}$. The cups were then washed 5 times with PBS containing $0.1 \%$ human albumin and then IgG anti-PA antibody radiolabelled with ${ }^{125} \mathrm{I}$ was added and incubated for 18 hours at $4^{\circ} \mathrm{C}$. After four further washes with the PBS-albumin buffer, the autoanalyser cups were counted for one minute and counts per minute corrected for background were calculated. Preformed PA antigen containing IC were suspended in $50 \%$ normal human serum and used as positive controls; sera from 9 children with no history of PA infection who had been investigated for coeliac disease were the negative controls.

Statistical methods. Results were analysed using the statistical package for the social sciences ${ }^{15}$ at University of London Computer Centre by Student's $t$ test, Pearson's least squares regressions ( $r$, and analysis of variance by the multiple regression method.

\section{Results}

Pseudomonas antigens in complexes. More complexed PA antigen was detected in the sera of the $69 \mathrm{CF}$

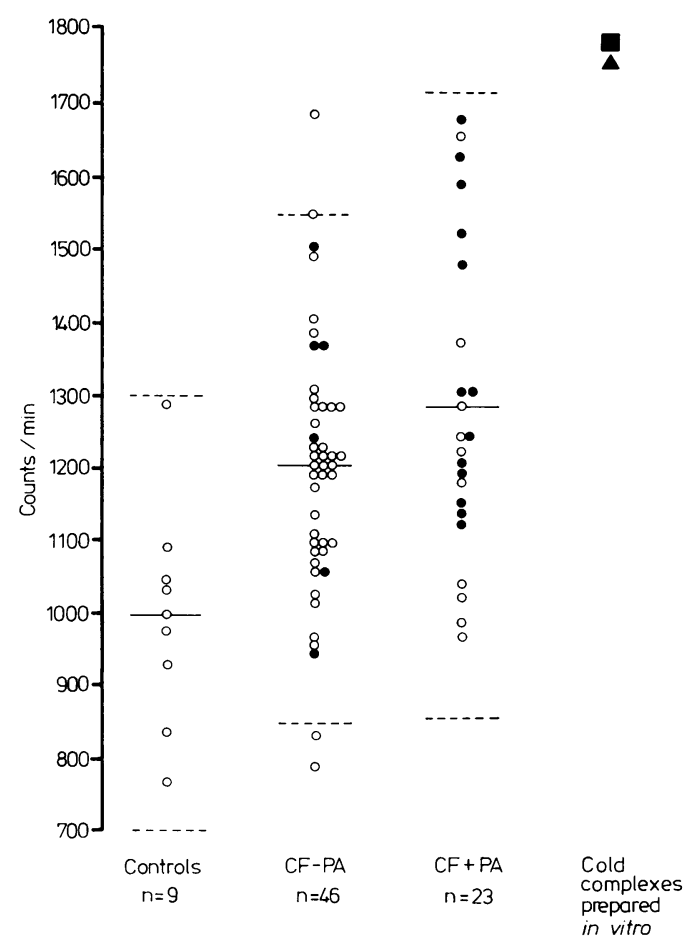

Figure Levels of complexed $\mathrm{P}$. aeruginosa antigen in $23 \mathrm{CF}$ children with chronic $\mathrm{P}$. aeruginosa colonisation of the lungs $(C F+P A), 46 C F$ children without such colonisation $(C F-P A)$, and in 9 age-matched controls. $C F$ children with acute exacerbations of pulmonary infection (๑) had significantly higher levels than patients who were well $(O) ;(t=2 \cdot 51, P<0 \cdot 02)$.

patients than in the 9 patients investigated for coeliac disease (Figure) $(t=4 \cdot 16, \mathrm{P}<0 \cdot 001)$. Sixteen $\mathrm{CF}$ patients had levels greater than 2 SDs above the mean of the controls but the amount of complexed antigen did not differ significantly between the CF patients chronically colonised with PA and those who were not $(t=1.62, \mathrm{P}>0.05)$, although it was significantly higher in patients with acute exacerbations of pulmonary infection than in those who were well when studied $(t=2 \cdot 51, \mathrm{P}<0 \cdot 02)$.

Circulating immune complexes. The mean value of Clq BA in the $69 \mathrm{CF}$ patients was $4.7 \%$ which is above our normal upper limit ${ }^{16}$ (Table 1) and 36 patients had Clq BA values outside this range. Clq BA was significantly increased in patients chronically colonised with PA (Table 2). No CF patient exceeded the normal range for IgG IC by PEG precipitation; however 2 patients had increased IgM IC (greater than $12.8 \%$ of serum IgM). It 
Table 1 Immune complex levels in 69 patients with cystic fibrosis compared with controls

\begin{tabular}{lll}
\hline & $\begin{array}{l}\text { Cystic fibrosis } \\
\text { patients }\end{array}$ & Controls \\
\hline Clq binding assay (\%), mean (SE) & $4 \cdot 7(0 \cdot 2)$ & $2 \cdot 1(0 \cdot 2)$ \\
Range & $2 \cdot 4-11 \cdot 8$ & $\leq 4 \cdot 0^{*}$ \\
IgG immune complexes (\%), mean (SE) & $1 \cdot 3(0 \cdot 1)$ & $2 \cdot 3(0 \cdot 1)$ \\
Range & $0 \cdot 0-2 \cdot 8$ & $1 \cdot 0-3 \cdot 5$ \\
IgM immune complexes (\%), mean (SE) & $5 \cdot 9(0 \cdot 3)$ & $5 \cdot 7(0 \cdot 4)$ \\
Range & $1 \cdot 6-17 \cdot 8$ & $0 \cdot 0-12 \cdot 8$ \\
\hline
\end{tabular}

* Determined as the upper limit of normal for our laboratory, 16 measured in 84 uninfected children admitted for cardiac surgery. Clq binding assay expressed as percentage of radioactive counts precipitated by $10 \%$ trichloroacetic acid. IgM and IgG immune complexes expressed as percentage of the immunoglobulin concentration in original serum.

Table 2 Immune complexes, immunoglobulin concentrations, and lung function in 25 CF patients chronically colonised with $\mathrm{P}$. aeruginosa and in 44 CF patients without such infection

\begin{tabular}{lll}
\hline & \multicolumn{2}{l}{ Cystic fibrosis patients } \\
\cline { 2 - 3 } & $\begin{array}{l}\text { Colonised with } \\
\text { P. aeruginosa }\end{array}$ & $\begin{array}{l}\text { Free of } \\
\text { P. aeruginosa } \\
\text { colonisation }\end{array}$ \\
\hline Clq binding assay (\%) mean (SD) & $5 \cdot 62(2 \cdot 20)^{* * *}$ & $4 \cdot 11(0 \cdot 96)$ \\
IgG immune complexes (\%) & $1 \cdot 42(0 \cdot 60)$ & $1 \cdot 21(0 \cdot 46)$ \\
mean (SD) & & \\
IgM immune complexes (\%) & $6 \cdot 74(3 \cdot 25)$ & $5 \cdot 36(1 \cdot 75)$ \\
mean (SD) & $204(60)^{* * *}$ & $139(52)$ \\
IgG (IU/ml) mean (SD) & $141(64)^{* *}$ & $95(67)$ \\
IgA (IU/ml) mean (SD) & $170(93)^{* * *}$ & $116(42)$ \\
IgM (IU/ml) mean (SD) & $25(9)^{* * *}$ & $67(27)$ \\
FEF25 $(\%$ predicted) mean (SD) & $55(13)^{* * *}$ & $37(9)$ \\
RV/TLC (\%) mean (SD) & &
\end{tabular}

***P<0.005, **P<0.01.

Clq binding assay, IgG immune complexes, IgM immune complexes results expressed as in Table 1 .

Serum IgG, IgA, IgM concentrations expressed as $\mathrm{IU} / \mathrm{ml}$.

FEF 25 forced expiratory flow at $25 \%$ of vital capacity, RV/TLC=

ratio of residual lung volume to total lung capacity. appeared, therefore, that Clq BA was more sensitive to the abnormalities in these patients than the PEG precipitation method.

Immunoglobulin levels. The mean level of serum IgG was $163 \mathrm{IU} / \mathrm{ml}(\mathrm{SE} \mathrm{7.6)}$ ) and the mean serum IgM $136 \mathrm{IU} / \mathrm{ml}$ (SE 8.4); both exceeded the means of age-matched British schoolchildren. ${ }^{17}$ Seven CF children had reduced serum IgA concentrations for age and 2 had levels that were hardly detectable. Many patients had hypergammaglobulinaemia as described in our earlier study ${ }^{\mathbf{1 8}}$ and all measured classes of immunoglobulin were significantly increased in CF children with chronic PA colonisation (Table 2).

Lung function. The mean $\mathrm{FEF}^{25}$ in the 54 of $69 \mathrm{CF}$ children for whom data were available was $49 \%$ of that predicted for height, and the mean RV/TLC in 49 cases was $45 \%$. There was a pronounced difference in both values according to whether or not the patients were chronically colonised with PA (Table 2).

Correlation analysis. Many of the observations were significantly intercorrelated (Table 3 ). As previously reported $^{9} 10$ there was a significant negative correlation between immunoglobulin levels and Clq BA and lung function. This was also observed for IgM IC but not for IgG IC or PA antigen containing IC. However, with such multiple intercorrelation it was possible that there was a single causative factor with many secondary effects and it seemed likely that PA colonisation was the primary abnormality. We therefore reanalysed the data by analysis of variance so that $\mathrm{FEF}^{25}$ and $\mathrm{RV} / \mathrm{TLC}$ were adjusted for the influence of chronic PA colonisation. When this was done there was no residual negative correlation between Clq BA, IgG, and IgM, and lung

Table 3 Correlation coefficients $(r)$ in 69 children with cystic fibrosis

\begin{tabular}{|c|c|c|c|c|c|c|c|c|}
\hline & $\begin{array}{l}\text { Clq } \\
\text { binding } \\
\text { assay }\end{array}$ & $\begin{array}{l}\text { IgG } \\
\text { immune } \\
\text { complexes }\end{array}$ & $\begin{array}{l}\text { IgM } \\
\text { immune } \\
\text { complexes }\end{array}$ & $I g G$ & $\operatorname{Ig} A$ & $I g M$ & $F E F^{25}$ & $R V / T L C$ \\
\hline IgC immune complexes & $\begin{array}{l}0 \cdot 36^{* * *} \\
(69)\end{array}$ & & & & & & & \\
\hline IgM immune complexes & $\begin{array}{l}0 \cdot 28^{* *} \\
(69)\end{array}$ & $\begin{array}{l}0 \cdot 56^{* * * *} \\
(69)\end{array}$ & & & & & & \\
\hline IgG & $\begin{array}{l}0.45^{* * * *} \\
(69)\end{array}$ & $\begin{array}{l}0 \cdot 11 \mathrm{NS} \\
(69)\end{array}$ & $\begin{array}{c}-0.04 \mathrm{NS} \\
(69)\end{array}$ & & & & & \\
\hline IgA & $\begin{array}{l}0 \cdot 12 \mathrm{NS} \\
(69)\end{array}$ & $\begin{array}{l}0.05 N S \\
(69)\end{array}$ & $\begin{array}{l}0.03 \mathrm{NS} \\
(69)\end{array}$ & $\begin{array}{l}0.53^{* * *} \\
(69)\end{array}$ & & & & \\
\hline IgM & $\begin{array}{l}0 \cdot 32^{* *} \\
(69)\end{array}$ & $\begin{array}{l}0.15 \mathrm{NS} \\
(69)\end{array}$ & $\begin{array}{l}0.04 \mathrm{NS} \\
(69)\end{array}$ & $\begin{array}{l}0.59 * * * \\
(69)\end{array}$ & $\begin{array}{l}0 \cdot 39 * * * \\
(69)\end{array}$ & & & \\
\hline FEF 25 & $\begin{array}{c}-0.31^{*} \\
(54)\end{array}$ & $\begin{array}{l}0 \cdot 17 \mathrm{NS} \\
(54)\end{array}$ & $\begin{array}{c}-0 \cdot 12 \mathrm{NS} \\
(54)\end{array}$ & $\begin{array}{c}-0 \cdot 50^{* * *} \\
(54)\end{array}$ & $\begin{array}{l}0 \cdot 37^{* *} \\
(54)\end{array}$ & $\begin{array}{c}-0 \cdot 29 * \\
(54)\end{array}$ & & \\
\hline RV/TLC & $\begin{array}{l}0 \cdot 32^{*} \\
(49)\end{array}$ & $\begin{array}{l}0.21 \mathrm{NS} \\
(49)\end{array}$ & $\begin{array}{l}0.29^{*} \\
(49)\end{array}$ & $\begin{array}{l}0 \cdot 31^{*} \\
(49)\end{array}$ & $\begin{array}{l}0 \cdot 34^{* *} \\
(49)\end{array}$ & $\begin{array}{l}0 \cdot 26^{*} \\
(49)\end{array}$ & $\begin{array}{l}-0 \cdot 59^{* * * *} \\
(47)\end{array}$ & \\
\hline
\end{tabular}

The number of valid cases for each correlation is shown in brackets.

***P $<0.005, \quad$ ** $P<0.01, \quad * P<0.05$. 
Table 4 Variance ratios $(F)$ in analysis of variance on lung function in cystic fibrosis

\begin{tabular}{|c|c|c|c|c|c|c|c|}
\hline $\begin{array}{l}\text { Dependent } \\
\text { variables }\end{array}$ & $\begin{array}{l}\text { No of } \\
\text { cases }\end{array}$ & $\begin{array}{l}\text { Pseudomonas } \\
\text { colonisation }\end{array}$ & $\begin{array}{l}\text { Clq binding } \\
\text { assay }\end{array}$ & $I g G$ & $\operatorname{Ig} A$ & $I g M$ & Age \\
\hline $\begin{array}{l}\text { FEF25 } \\
\text { RV/TLC }\end{array}$ & $\begin{array}{l}44 \\
59\end{array}$ & $\begin{array}{l}31 \cdot 4^{* * *} \\
16 \cdot 9^{* * *}\end{array}$ & $\begin{array}{l}0.2 \\
0.8\end{array}$ & $\begin{array}{l}2 \cdot 7 \\
0 \cdot 4\end{array}$ & $\begin{array}{l}0.5 \\
4 \cdot 6^{*}\end{array}$ & $\begin{array}{l}0.5 \\
0 \cdot 16\end{array}$ & $\begin{array}{l}3 \cdot 8 \\
\text { NI }\end{array}$ \\
\hline
\end{tabular}

***P<0.001, *P<0.05.

$\mathrm{NI}=$ not included, as not significant in earlier study. ${ }^{3}$

function (Table 4) although IgA still correlated inversely with RV/TLC (but less so than before).

\section{Discussion}

Abnormal levels of circulating IC have been reported before in patients with $\mathrm{CF}^{5-10}$ and it has been proposed that secondary lung damage may be the result of localised immune complex deposition. ${ }^{5} 710$ IC have also been demonstrated in the sputum of CF patients ${ }^{19}$ and there is a single report of granular deposition of immunoglobulins and complement components in the trachea and lungs of a CF patient. ${ }^{20}$

Pulmonary colonisation with PA is highly prevalent in $\mathrm{CF}$ so it was possible that the IC contained PA antigens; indeed haemagglutinating antibodies to PA lipopolysaccharide have been demonstrated in such IC. ${ }^{8}$ We have demonstrated the presence of PA antigens within the IC isolated from CF sera by PEG precipitation but there was no significant correlation between these PA antigens containing IC and either poor lung function or overt PA lung colonisation, whereas PA IC were significantly increased in patients with acute exacerbations of pulmonary infection. It was surprising that levels of PA containing IC were not significantly increased in patients chronically colonised with PA. This may reflect either under-diagnosis of PA by standard microbiological methods and our definition of 'chronic colonisation' or intermittent PA infection, perhaps in other sites such as paranasal sinuses. The first of these possibilities is supported by the observation that the 2 patients with the highest levels of PA antigen containing IC in the uncolonised group became persistently colonised soon afterwards. None the less, we have established that the circulating IC in CF may contain PA antigens and that persistent antigenaemia can occur in patients with negative sputum cultures.

These results of IC investigations in CF are compatible with those of earlier studies. ${ }^{5-10}$ Our further analysis suggests however, that although circulating IC and impaired pulmonary function are correlated in CF, this correlation is not significant when the effect of PA is allowed for by analysis of variance. The relationship of lung disease to hypergammaglobulinanaemia was similar to that with circulating IC and, therefore, no independent direct relationship was established between either of these immunological phenomena and pulmonary disease. Conversely, we were unable to confirm the reported association of good lung function and subnormal immunoglobulin concentrations ${ }^{21}$ when the effect of infection was taken into account.

PA colonisation is the main factor associated with poor lung function. ${ }^{23}$ Such pulmonary damage could be the effect of exotoxins, proteases, or any of the immunological mediators of inflammation. ${ }^{22}$ It is also possible that pulmonary damage could result from in situ formation of IC, but our data suggest that circulating IC are not important. However, serum levels of IC in our CF children seemed to be lower than those seen in series which included adults ${ }^{56-10}$ for whom the situation may be different. There was a significant correlation of serum IgA with RV/TLC even when the latter was adjusted for the influence of PA; we interpret this as the effect of other infections. The findings of this study therefore strengthen the view that PA colonisation is of critical importance in $\mathrm{CF}^{2}{ }^{3}$

We thank Dr Ty Pitt of the Central Public Health Laboratory, London, for the PA antigen and antiserum.

R W P-W was supported by the Cystic Fibrosis Research Trust, and R J L by the Nuffield Foundation.

\section{References}

1 Wood R E, Boat T F, Doershuk C F. Cystic fibrosis. Am Rev Respir Dis 1976; 113: 833-78.

${ }^{2}$ Hoiby N, Winge Flensborg E, Beck B, Friis B, Vidar Jacobsen S, Jacobsen L. Pseudomonas aeruginosa infection in cystic fibrosis. Diagnostic and prognostic significance of Pseudomonas aeruginosa precipitens determined by means of crossed immunoelectrophoresis. Scand J Respir Dis 1977 ; 58: 65-79.

3 Pitcher-Wilmott $R$ W, Levinsky $R$ J, Gordon I, Turner M W, Matthew D J. Pseudomonas infection, allergy, and cystic fibrosis (abstract). Eur J Pediatr 1981; 137: 122.

4 Doggett R G, Harrison G M. Pseudomonas aeruginosa; immune status in patients with cystic fibrosis. Infect Immun 1972; 6: 628-35. 
5 Church J A, Jordan S C, Keens T G, Wang C-I. Circulating immune complexes in patients with cystic fibrosis. Chest $1981 ; 80: 405-11$.

6 Moss R B, Lewiston N J. Immune complexes and humoral response to Pseudomonas aeruginosa in cystic fibrosis. Am Rev Respir Dis 1980; 121 : 23-9.

7 Schiotz P O, Hoiby N, Juhl F, Permin H, Nielsen $\mathbf{H}$, Svehag S E. Immune complexes in cystic fibrosis. Acta Pathol Microbiol Scand $[C] 1977 ; 85$ : 57-64.

8 Berdischewsky M, Pollack M, Young L S, Chia D, Osher A B, Barnett E V. Circulating immune complexes in cystic fibrosis. Pediatr Res 1980; 14: 830-3.

9 Beldon I, Hodson M E, Batten J C. Circulating immune complexes in the sera of patients with cystic fibrosis. In: Sturgess J M, ed. Perspectives in cystic fibrosis. Proceedings of the Eighth International Congress on Cystic Fibrosis (abstract). Toronto: Canadian Cystic Fibrosis Foundation, 1980:3a.

10 Moss R B, Yao-Pi Hsu M S, Lewiston N J. ${ }^{125}$ I-Clqbinding and specific antibodies as indicators of pulmonary disease activity in cystic fibrosis. $J$ Pediatr 1981; 99: 215-22.

11 Mancini G, Carbonara A O, Heremans J F. Immunochemical quantitation of antigens by single radial immunodiffusion. Immunochemistry 1965; 2 : 235-54.

12 Zubler R H, Lange G, Lambert P H, Miescher P A. Detection of immune complexes by modified ${ }^{125} \mathrm{I}-\mathrm{Clq}$ binding test. Effects of heating on the Clq binding by immune complexes and application of the test to systemic lupus erythematosus. J Immunol 1976; 116: 232-5.

13 Dambuyant C, Burton-Kee J, Mowbray J F. Demonstration of two disease specific antigens in circulating immune complexes. Clin Exp Immunol 1979; 37: 424-31.

14 Paganelli R, Levinsky R J, Atherton D J. Detection of specific antigen within circulating immune complexes. Validation of the assay and its application to food antigen-antibody complexes formed in healthy and foodallergic subjects. Clin Exp Immunol 1981 ; 46: 44-53.

15 Nie N H, Hadlai Hull C, Jenkins J G, Steinbrenner K, Bert D H. Statistical package for the social sciences, second edition. New York: McGraw-Hill, 1975.

16 Paganelli R, Levinsky R J, Brostoff J, Wraith D G. Immune complexes containing food proteins in normal and atopic subjects after oral challenge and effect of sodium cromoglycate on antigen absorption. Lancet $1979 ; \mathbf{i}: 1270-2$.

17 Hobbs J R. Simplified radial immunodiffusion. Association of Clinical Pathologists 1970, Broadsheet No 68: 1-8.

18 Turner M W, Warner J O, Stokes C R, Norman A P. Immunological studies in cystic fibrosis. Arch Dis Child 1978; 53: 631-8.

19 Schiotz PO, Nielsen H, Hoiby N, Glikmann G, Svehag S E. Immune complexes in the sputum of patients with cystic fibrosis suffering from chronic Pseudomonas aeruginosa lung infection. Acta Pathol Microbiol Scand $[C]$ 1978; 86: 37-40.

20 McFarlane $\mathrm{H}$, Holzel A, Brenchley $\mathrm{P}$, et al. Immune complexes in cystic fibrosis. $\mathrm{Br}$ Med J 1975; i: 423-8.

21 Matthews W J, Jr, Williams M, Oliphint B, Geha R, Colten H R. Hypogammaglobulinemia in patients with cystic fibrosis. N Engl J Med 1980; 302: 245-9.

22 Marks M I. The pathogenesis and treatment of pulmonary infections in patients with cystic fibrosis. J Pediatr 1981; 98: $173-9$

Correspondence to Dr R J Levinsky, Department of Immunology, Institute of Child Health, Guilford Street, London WC1N 1EH.

Received 5 May 1982 